\title{
Host-Pathogen Co-Evolution: Chlamydia trachomatis Modulates Surface Ligand Expression in Genital Epithelial Cells to Evade Immune Recognition
}

\author{
Gerialisa Caesar ${ }^{1}$, Joyce A. Ibana ${ }^{2}$, Alison J. Quayle ${ }^{2}$ and Danny J. Schust ${ }^{1}$ \\ ${ }^{1}$ Department of Obstetrics, Gynecology and Women's Health, \\ University of Missouri School of Medicine, Columbia, MO \\ ${ }^{2}$ Department of Microbiology, Immunology and Parasitology, \\ Louisiana State University Health Sciences Center, New Orleans, LA
}

USA

\section{Introduction}

Chlamydia trachomatis (C. trachomatis) is an obligate intracellular bacterium that causes significant human disease (Everett, Bush et al. 1999). This pathogen is usually categorized by its major outer membrane protein (MOMP) antigen, and serovars $\mathrm{D}$ though $\mathrm{K}$ infect the mucosal columnar epithelial cells of the urogenital tract (Linhares and Witkin 2010). Though C. trachomatis infection can be treated using several antibiotic regimens, the World Health Organization considers it to be the world's most common bacterial sexually transmitted disease, infecting approximately 90 million people worldwide (Gerbase, Rowley et al. 1998). In 2010, the Center for Disease Control reported the rate of chlamydial infection in women as 592.2 cases per 100,000 in the US. In contrast, only 219.3 cases per 100,000 men were reported(CDC 2010). Clearly there remains an urgent need for improved risk assessment tools, disease prevention strategies, reliable screening regimens and efficacious treatments if we are to control this highly prevalent disease.

Clinical presentation and disease sequelae after sexual transmission of $C$. trachomatis (serovars D-K) differ between men and women. In men, C. trachomatis infection is most typically symptomatic, is a common cause for urethritis and the much rarer syndrome of epididymitis(Peipert 2003), and is occasionally associated with impaired fertility(Idahl, Abramsson et al. 2007; Joki-Korpela, Sahrakorpi et al. 2009). C. trachomatis most commonly infects the endocervix in women, but the great majority (70-90\%) of cases are asymptomatic(Peipert 2003). Natural history studies indicate individuals can spontaneously clear C. trachomatis infection, but this can take several months to several years(Dean, Suchland et al. 2000). Importantly, infection in women may be complicated by ascending infection and endometritis and/or salpingitis \{reviewed in (Brunham and Rey-Ladino 2005)\}. Pelvic inflammatory disease (PID) is a too frequent end result of chlamydial infection of the female lower genital tract. While the final syndrome is most certainly multibacterial, Neisseria gonorrheae and C. trachomatis are frequent inciting factors (Paavonen and Lehtinen 1996). PID is an ascending genital infection from the cervix to the upper genital tract with 
infectious spill into the female peritoneal cavity. The disease can result in scarring and pelvic organ disfigurement that lead to increases in ectopic pregnancy rates, tubal factor infertility (Hellstrom, Schachter et al. 1987) and possibly early pregnancy wastage (Witkin 1999). If left untreated during pregnancy, chlamydial genital infections in women have been associated with preterm delivery (Rours, Duijts et al. 2011).

\section{Developmental cycle of Chlamydia trachomatis}

Chlamydia exhibits a predominantly biphasic developmental cycle, differentiating between a metabolically inactive but infectious elementary body (EB) and a replicating and metabolically active, but non-infectious, reticulate body (RB) (Nelson, Virok et al. 2005; Linhares and Witkin 2010). Attachment and entry of EBs into permissive cells are critical steps in chlamydial development, but the molecules and mechanisms utilized in these processes are not well understood. Several bacterial ligands have been implicated as adhesins, and include heparin sulfate-like proteins, MOMP, OmcB, glycoproteins and Hsp70 (reviewed by Hackstadt 1999). The host factor/s involved in attachment is/are likely proteinacious, and the host cytoplasmic chaperone protein disulfide isomerase (PDI) has been strongly implicated as a structural requirement for attachment of multiple serovars, as well as necessary for entry (Davis, Raulston et al. 2002; Conant and Stephens 2007; Abromaitis and Stephens 2009). After EB internalization, Chlamydia-derived vesicles mature into a specialized parasitophorous vacuole termed an inclusion, which is nonfusogenic with lysosomal and endosomal membranes (Fields, Fischer et al. 2002; Carabeo, Mead et al. 2003; Hybiske and Stephens 2007a; Hybiske and Stephens 2007b). The exact mechanisms involved in the differentiation of the chlamydial EB into a RB remain incompletely described, but morphological investigations have demonstrated decondensation of chromatin occurs early in the process and supports the transition from a metabolically inert EB to a metabolically active RB (Beatty, Byrne, et al. 1993; Beatty, Morrison, et al. 1995; Belland, Zhong et al. 2003) Elegant investigations using transcriptional profiling have listed chaperonin, metabolite translocation, metabolite interconversion, endosomal trafficking, and inclusion membrane modification genes to be among the first to be activated (immediate early genes) during this transition (Belland, Zhong, et al. 2003; AbdelRahman and Belland 2005). As might have been predicted, these genes fall into categories required for pathogen acquisition of nutrients and for inhibiting fusion of the chlamydial inclusion with the host cell lysosomal pathway. Inside the inclusion, the elementary bodies differentiate into reticulate bodies that, in turn, divide rapidly via binary fission. $\mathrm{RB}$ condense back into $\mathrm{EB}$ and completion of the chlamydial cell cycle results in EB release by host cell lysis or extrusion (Todd and Caldwell 1985; ; Hybiske and Stephens 2007b). Secondary differentiation of RB back into EB involves late gene expression and includes genes that direct recondensation of chromosomes, production of the outer membrane complex and even a number of genes previously described as immediate early genes (Nicholson, Olinger et al. 2003; AbdelRahman and Belland 2005). This latter finding appears to suggest that the EB is readying itself for its next cycle of attack. Newly-released, re-differentiated EB are thence able to infect nearby epithelial cells.

\section{Chlamydial persistence}

The term "persistence" has been used to describe an alternative in vitro pattern of chlamydial growth during which the bacteria cannot be cultivated, but remain viable for 
extended periods of time (Beatty, Belanger et al. 1994; Belland, Nelson et al. 2003). Persistence is characterized by the presence of large, morphologically aberrant RB within the inclusion (Beatty, Morrison et al. 1995). While the chlamydial chromosomes can continue to divide in these aberrant RB in vitro, replication by binary fission does not occur nor does redifferentiation into EB (Beatty, Morrison et al. 1995). To date, there is no direct evidence that persistence occurs in vivo. That said, in vivo persistence is suggested by several clinical findings. Firstly investigators have shown that chlamydial antigens and nucleic acids can be detected in tissues that do not support cultivable growth (Holland, Hudson et al. 1992; Patton, Askienazy-Elbhar et al. 1994). Second, multiple, same-serovar recurrent C. trachomatis infections have been observed in a cohort of women over a 2-5 year period despite antibiotic treatment (Dean, Suchland et al. 2000). Thirdly, gynecologic and primary care clinicians frequently encounter recurrent chlamydial disease when re-infection is highly unlikely (e.g., no longer sexually active; prior tubal ligation surgery) again suggesting longterm dormancy of chlamydial forms. The induction of persistence has been implicated in chlamydial immune evasion and pathogenesis (Beatty, Byrne et al. 1993; Beatty, Byrne et al. 1994; Beatty, Morrison et al. 1994). We hypothesize that the ability of C. trachomatis to enter into a persistent growth form in vivo might represent a balance between host and pathogen struck through many years of co-evolution. The fact that persistent chlamydial forms are non-infectious could limit their immune detection for extended periods of time, and thereby limit immune-mediated damage. The fact that persistent chlamydial forms can be rapidly induced to return to the typical developmental cycle with removal of growth stressors in vitro (Beatty, Morrison et al. 1995; Belland, Nelson et al. 2003) would also suggest bacteria could successfully survive what might otherwise be lethal exogenous or host-induced stressors.

A variety of stressors can cause $C$. trachomatis to enter into persistent growth in vitro. These include exposure to antibiotics such as penicillin and ampicillin, interferon gamma (IFN $\gamma$ ) and nutrient depletion (Clark, Schatzki et al. 1982; Beatty, Byrne et al. 1993; Belland, Nelson et al. 2003; Wyrick 2010). While most in vitro persistence models are in transformed cell lines, persistent chlamydial forms have recently been induced in primary human endocervical epithelial cell cultures using ampicillin (Wang, Frohlich et al. 2011). While ampicillin and penicillin are not used in treatment of chlamydial infections, it has been noted that the widespread use of these antibiotics for control of other infections could inadvertently encourage the development of persistent forms in infected, undiagnosed individuals (Wyrick 2010). It is also a possibility that improper dosage and exposure duration of appropriate antibiotics for treatment of $C$. trachomatis may divert chlamydial organisms into the persistence pathway; indeed the presence of morphologic variants of $C$. trachomatis has been documented in the genital tissues of a small proportion of men and women treated with azithromycin (Bragina, Gomberg et al. 2001).

Cytokines secreted by local phagocytes, NK cells and T cells are important in immune defense against infection. These same cytokines, however, may also be implicated in disease pathogenesis. For many pathogens, including C. trachomatis, IFN $\gamma$ plays an important role in resolution of infection (Marks, Tam et al. 2010; Agrawal, Bhengraj et al. 2011; Matthews, Wilkinson et al. 2011; Ohman, Tiitinen et al. 2011; Patel, Stefanidou et al. 2011). The role of IFN $\gamma$ in chlamydial clearance is complicated by the fact that inflammation can damage host cells and IFN $\gamma$ itself can also drive persistence (Beatty, Belanger et al. 1994). IFN $\gamma$ exposure induces the expression of indoleamine 2,3-dioxygenase (IDO) in various types of epithelial 
cells (Feng and Taylor 1989). The IFN $\gamma$-mediated induction of IDO facilitates the catabolism of tryptophan to kynurenine (Beatty, Belanger et al. 1994). C. trachomatis is a tryptophan auxotroph, and continuous exposure to IFN $\gamma$ at inhibitory concentrations results in the eradication of the bacteria (Byrne and Krueger, 1983). However, exposure to sub-inhibitory IFN $\gamma$ concentrations, which may be a likely scenario in vivo, induces chlamydial organisms to enter a persistent phase, with characteristic aberrant inclusions and the presence of small, non-replicating RB (Byrne and Krueger 1983). A potential therapeutic problem associated with IFN $\gamma$-induced persistence is the reduced bactericidal activity of doxycycline against these aberrant growth forms as demonstrated by Reveneau et al., in vitro (Reveneau, Crane et al. 2005). We (Ibana, Nagamatsu et al. 2011) have recently demonstrated that levo-methyl-tryptophan (L-1MT), an IDO inhibitor, prevents IFN $\gamma$-induced $C$. trachomatis persistence without resulting in productive multiplication of the bacterium. L-1MT also improved the efficacy of doxycycline against the IFN $\gamma$-induced C. trachomatis persistent forms, and may thus provide a novel approach to clear doxycycline-resistant forms of the bacterium.

Although persistence has not been definitively demonstrated in vivo, in vitro modeling has suggested a role for persistent chlamydial forms in disease pathogenesis. While synthesis of many of the antigenic outer membrane antigens is decreased in in vitro persistence models (Beatty, Morrison et al. 1995), persistent organisms do replicate their chromosomal material and they remain metabolically active (Belland, Nelson et al. 2003). In fact, persistent organisms induced by IFN $\gamma$ and penicillin exposure continue to produce and secrete the 60 kDa chlamydial heat shock protein, CHSP60 (Beatty, Byrne et al. 1993; Beatty, Morrison et al. 1995; Linhares and Witkin 2010). Although circulating antibodies against C. trachomatis membrane associated proteins (MOMPs) have been linked to infertility, the presence of antiCHSP60 antibodies appears to be more sensitive and specific for the disease (Linhares and Witkin 2010; Stephens, Aubuchon et al. 2011). The presence of anti-CHSP60 IgA antibodies in the cervical secretions of women undergoing IVF has been associated with decreased live birth rates (Witkin 1999) and the presence of circulating IgG to CHSP60 in women with prior ectopic pregnancy has been linked repeat ectopic pregnancy and other adverse pregnancy outcomes (Sziller, Fedorcsak, et al 2008). To explain these findings, it has been hypothesized that prolonged exposure to CHSP60 may break tolerance to the human HSP60 that is normally expressed by normal human embryos (Linhares and Witkin 2010, Stephens, Aubuchon et al. 2011).

\section{Pathogen immune evasion}

Millions of years of co-evolution have benefitted many pathogens and their hosts. Constantly changing pathogenic challenges allowed hosts to develop efficient, effective, redundant and advanced immune systems. The evolving host has driven the successful pathogen to develop strategies to evade detection by the host immune systems. At times, immune detection is evaded just long enough to enable a complete pathogen replication cycle with spread of progeny to surrounding cells. For other pathogens, immune evasion allows for prolonged and even lifelong pathogen persistence.

Exogenous pathogens, whether they are viral or bacterial, typically encounter several barriers to infection and successful pathogens have adapted to breech these barriers. For most pathogens, the first of these obstacles involves surviving in a local mucosal 


\begin{tabular}{|c|c|c|c|c|c|}
\hline $\begin{array}{l}\text { Immune } \\
\text { Effector Cell } \\
\text { Type }\end{array}$ & $\begin{array}{l}\text { Host Cell } \\
\text { Ligand }\end{array}$ & $\begin{array}{l}\text { Immune Cell } \\
\text { Ligand }\end{array}$ & $\begin{array}{l}\text { Function of } \\
\text { Mucosal Immune } \\
\text { Cell }\end{array}$ & $\begin{array}{l}\text { Mechanism of } \\
\text { Pathogen } \\
\text { Recognition }\end{array}$ & $\begin{array}{l}\text { C. Trachomatis } \\
\text { Evasion Strategy }\end{array}$ \\
\hline $\begin{array}{l}\text { CD8+ T cell } \\
\text { recognition } \\
\text { (adaptive } \\
\text { immunity) }\end{array}$ & MHC class I & $\mathrm{T}$ cell receptor & $\begin{array}{l}\text { Response to } \\
\text { altered self or to } \\
\text { cytosolic, } \\
\text { pathogen - } \\
\text { derived antigens }\end{array}$ & $\begin{array}{l}\text { IDO induces } \\
\text { IFN } \gamma \text {-mediated } \\
\text { increases in host } \\
\text { MHC class I } \\
\text { expression at } \\
\text { the cell surface }\end{array}$ & $\begin{array}{l}\text { CPAF-mediated } \\
\text { degradation of } \\
\text { RFX-5, which is } \\
\text { essential for } \\
\text { IFNץ-induced } \\
\text { MHC class I } \\
\text { expression } \\
\text { Amino-terminal } \\
\text { CPAF fragment } \\
\text { (CPAFn) directly } \\
\text { involved }\end{array}$ \\
\hline $\begin{array}{l}\mathrm{CD} 4+\mathrm{T} \text { cell } \\
\text { recognition } \\
\text { (adaptive } \\
\text { immunity) }\end{array}$ & MHC class II & $\mathrm{T}$ cell receptor & $\begin{array}{l}\text { Response to } \\
\text { extracellular/ } \\
\text { endosomal } \\
\text { pathogens }\end{array}$ & $\begin{array}{l}\text { IFNץ increases } \\
\text { MHC class II } \\
\text { (HLA-DR) } \\
\text { expression } \\
\text { on infected host } \\
\text { cells }\end{array}$ & $\begin{array}{l}\text { CPAF-mediated } \\
\text { degradation of } \\
\text { USF1, a } \\
\text { transcription } \\
\text { factor important } \\
\text { for MHC class II } \\
\text { expression. } \\
\text { Carboxy- } \\
\text { terminal } \\
\text { fragment } \\
\text { (CPAFC) directly } \\
\text { involved }\end{array}$ \\
\hline $\begin{array}{l}\text { Natural Killer } \\
\text { Cell } \\
\text { recognition } \\
\text { (innate } \\
\text { immunity) }\end{array}$ & $\begin{array}{l}\text { MHC class I } \\
\text { (non-antigen } \\
\text { dependent) }\end{array}$ & $\begin{array}{l}\text { Killer } \\
\text { inhibitory } \\
\text { receptors } \\
\text { (KIRs; } \\
\text { inhibitory) } \\
\text { NKG2D } \\
\text { (activating) } \\
\text { others }\end{array}$ & $\begin{array}{l}\text { Self/non-self } \\
\text { recognition; } \\
\text { Absence of self } \\
\text { signals } \\
\text { abnormality } \\
\text { Innate immunity }\end{array}$ & $\begin{array}{l}\text { Altered } \\
\text { expression of } \\
\text { self MHC class I } \\
\text { recognized by } \\
\text { NK expressed } \\
\text { inhibitory KIRs } \\
\text { Altered } \\
\text { expression of } \\
\text { MICA } \\
\text { recognized by } \\
\text { NK cell } \\
\text { expressed } \\
\text { activating } \\
\text { NKG2D }\end{array}$ & $\begin{array}{l}\text { MICA } \\
\text { expression } \\
\text { altered only in } \\
\text { directly-infected } \\
\text { cells }\end{array}$ \\
\hline $\begin{array}{l}\text { Natural Killer } \\
\text { T cells (innate } \\
\text { immunity) }\end{array}$ & CD1d & $\begin{array}{l}\mathrm{V} \alpha 24-\mathrm{J} \alpha \mathrm{Q} / \mathrm{V} \beta 11 \\
\text { Invariant T cell } \\
\text { receptor }\end{array}$ & $\begin{array}{l}\text { Response to lipid- } \\
\text { derived antigens. }\end{array}$ & $\begin{array}{l}\text { CD1d molecule } \\
\text { recognizes NKT } \\
\text { cell receptor } \\
\text { and produces } \\
\text { IFNץ. } \\
\text { IFN } \gamma \text { catabolizes } \\
\text { tryptophan and } \\
\text { aids in clearing } \\
\text { C. trachomatis } \\
\text { infection }\end{array}$ & $\begin{array}{l}\text { CPAF and } \\
\text { cellular } \\
\text { proteasome - } \\
\text { mediated } \\
\text { degradation of } \\
\text { host MHC class I } \\
\text { and CD1d } \\
\text { surface } \\
\text { expression } \\
\text { CPAF binds } \\
\text { directly to the } \\
\text { CD1d } \\
\text { cytoplasmic tail }\end{array}$ \\
\hline
\end{tabular}

Table 1. MHC and MHC-like ligands modulated by C. trachomatis to evade immune detection 
microenvironment and crossing the mucosal epithelial barrier. The common gastrointestinal bacterium, Heliobacter pylori, is particularly adept at this. H. pylori express a variety of colonization factors, including outer membrane adhesins, which allow the bacteria to survive in the acidic and mucus-filled gastrointestinal lumen and attach to epithelial cell surfaces (Fischer, Prassl et al. 2009). Once the epithelial barrier has been breached, pathogens must next surmount innate immune detection. Such detection includes recognition by the host complement system and by host macrophages, dendritic cells, monocytes, neutrophils and eosinophils (Ploegh 1998). The latter includes recognition through, among others, Toll-like receptors (TLRs), nucleotide-binding and oligomerization domain (NOD)-like receptors and helicases (Xiao 2010). Several bacteria, including Salmonella enterica, Escherichia coli and several Brucella species use molecular mimicry to evade host immune signaling and the innate immune recognition and clearance mediated by these cell surface receptors (Xiao 2010). Successful pathogens must next subvert, at least temporarily, those immune cells that straddle innate and adaptive immune functionality, including natural killer (NK) and natural killer T (NKT) cells (Table 1, Figure 1). Finally pathogens that have survived the previous obstacles will encounter the host adaptive immune response involving $\mathrm{B}$ and $\mathrm{T}$ cells and both immediate and memory responses. Intracellular pathogens, including most viruses, have developed a wide variety of immune evasion strategies. For example the human herpesviruses are characterized by their ability to establish latency in immunocompetent human hosts, often with infrequent or absent symptomatology. These DNA viruses comprise a large group of related pathogens with well-described but variable mechanisms for abrogating presentation of virus-derived antigens to host immune cells via major histocompatibility (MHC) class I molecules (Tortorella, Gewurz et al. 2000; Horst, Ressing et al. 2011). Extracellular pathogens are more likely to target antigen presentation by MHC class II molecules.

Historically, it was thought that chlamydial antigens were retained within the inclusion. More recent studies, however, have reported that both CD4+ and CD8+ T cells respond to chlamydial-derived antigens (Grotenbreg, Roan et al. 2008; Roan and Starnbach 2008; Finco, Frigimelica et al. 2011) suggesting that MHC class I and MHC class II antigen presentation are both involved in chlamydial recognition and that antigen cross-presentation or autophagy could be important in chlamydial clearance and possibly in chlamydial pathogenesis (Finco, Frigimelica et al 2011). We now know that chlamydial antigens access the host cell cytosol through a variety of mechanisms (Cocchiaro and Valdivia 2009). Wyrick et al. have shown in an elegant series of experiments that chlamydial antigens are present in the cytosol attached to vesicles that have everted from the C. trachomatis inclusion (Giles, Whittimore et al. 2006) and that C. trachomatis antigens can traffic to the endoplasmic reticulum (ER) of infected epithelial cells (Giles and Wyrick 2008). Interestingly, some of the chlamydial antigens that trafficked to the ER were seen to co-localize with the MHC-like molecule CD1d (see below) (Wyrick 2010). Others have shown that proteins such as the chlamydial outer membrane complex protein B (OmcB) (Qi, Gong et al. 2011) and the chlamydia protease, CPAF (see below), are present in the host cell cytosol (Sharma, Bosnic et al. 2004; Kawana, Quayle et al. 2007), the latter being secreted through a Sec-dependent pathway (Chen, Lei et al. 2010). C. trachomatis also uses the type III secretory system (T3SS) to move bacterial virulence proteins from EB into the host cytosol (Clifton, Fields et al. 2004; Hower, Wolf et al. 2009). Not surprisingly, C. trachomatis has devised immune evasion strategies to subvert host recognition of infection via MHC class I and MHC class II. While several additional mechanisms for pathogen evasion of host clearance have been reported 
(Betts, Wolf et al. 2009), we will concentrate here on C. trachomatis immune evasion via modulation of those surface-expressed ligands important in antigen presentation.

\section{Downregulation of MHC class I and II}

Chlamydial avoidance of adaptive immune responses involving CD8 ${ }^{+} \mathrm{T}$ cells and CD4 ${ }^{+} \mathrm{T}$ cell recognition (Van Voorhis, Barrett et al. 1996; Kelly, Walker et al. 2000; Rank, Bowlin et al. 2000) can involve pathogen-driven suppression of host cell surface expression of IFN $\gamma^{-}$ inducible MHC class I and II molecules at the site of infection (Fruh, Ahn et al. 1997). The major histocompatibility complex (MHC) is a polymorphic and polygenic host DNA region used by cells to produce and present 8-10 amino acid, self- and pathogen-derived peptides at the host cell surface. Altered self peptides (e.g., from neoplastic change) and pathogenderived peptides are antigenic and induce host immune response. The two most prominent products encoded by the MHC in humans are referred to as MHC class I and class II molecules (Figure 1). Each provides information to the host immune system on antigenic insults, although these insults conventionally differ in location. MHC class I molecules bind and present peptides at the host cell surface that are derived from altered self or from intracellular pathogens (typically within the host cytosol). In contrast, MHC class II molecules bind and present peptides from extracellular pathogens, whose destruction and processing typically occurs within the host cell endosome (Germain 1986). This relative dichotomy is challenged by the classical description of inclusion-sequestered chlamydiaderived antigens. As discussed above, there are many descriptions of cytosolic and extracellular (Campbell, Larsen et al. 1998) chlamydial antigens that now explain the detection of CD4+ and CD8+ T cell responses to chlamydial antigens (Figure 1).

The expression of MHC class I molecules on epithelial cells is up-regulated by IFNץ during most infections (Maudsley and Morris 1989). RFX, a transcription complex that binds to the promoter region of MHC class I and class II molecules is important for both constitutive and IFNy-inducible MHC class I expression in chlamydia infected cells (van den Elsen and Gobin 1999). Zhong, et al (Zhong, Liu et al. 2000) were the first to show that degradation of RFX5 occurred in cells infected with $C$. trachomatis L serovars and that such degradation inhibited both constitutive and IFNY-inducible MHC class I expression in infected cells. As predicted, cells from patients deficient in RFX 5, a sub-unit of RFX, exhibit reduced IFNYmediated induction of MHC class I expression (Gobin, Peijnenburg et al. 1998).

Chlamydia has also evolved a strategy for inhibiting IFN $\gamma$-inducible MHC class II expression. Here the pathogen degrades a ubiquitously expressed transcription factor

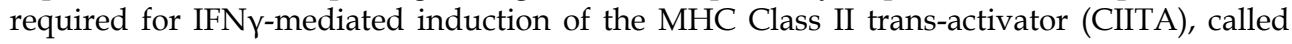
upstream stimulatory factor 1 (USF1) (Zhong, Fan et al. 1999). USF1 is a non-DNA-binding co-activator required for MHC class II expression (Chang, Fontes et al. 1994). A more detailed mechanism for this degradation was put forth with the discovery of its more generalized role in MHC degradation and is now known to involve a chlamydia-encoded proteasome-like activity factor (CPAF). CPAF is present in the cytosol of chlamydia-infected cells and is primarily responsible for the degradation of RFX5 and USF1 and subsequent down regulation of surface MHC class I and II expression, respectively. The active components of CPAF are a dimer consisting of a $29 \mathrm{kDa}$ amino-terminal fragment (CPAFn) and a 35KDa carboxy-terminal fragment $(\mathrm{CPAFc})$. Activity of the CPAFn fragment has been shown to be responsible for degradation of RFX5 (Zhong, Fan et al. 2001). With the very recent description of a specific inhibitor of CPAF (Bednar, Jorgensen et al. 2011) it is 


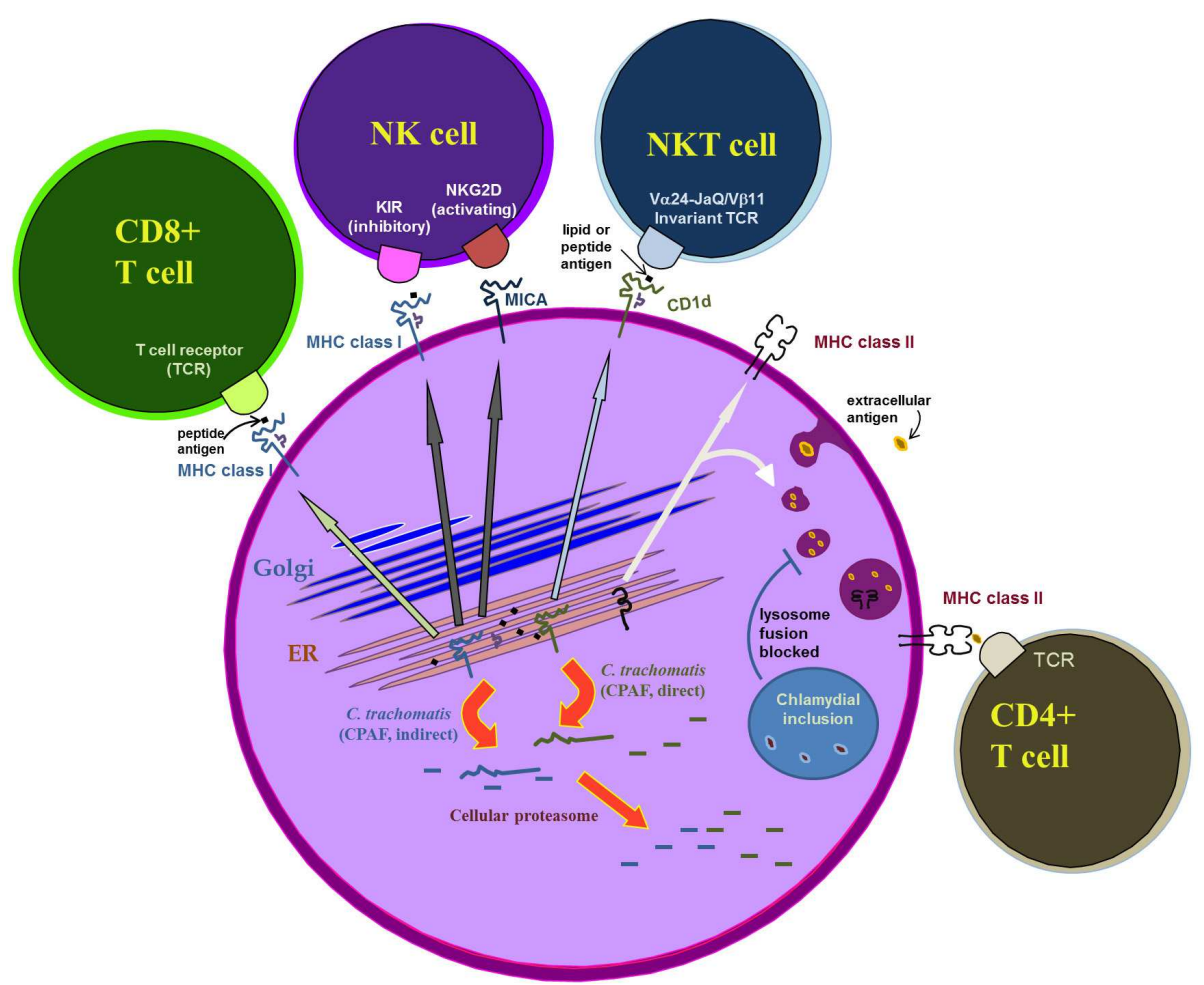

Fig. 1. Presentation of chlamydial antigens. Cytosolic antigens are degraded by the cellular proteasome into 8-10 amino acid peptide fragments that are actively transported into the lumen of the endoplasmic reticulum (ER). These antigenic peptides (depicted as short black lines) are loaded into the peptide binding groove of the MHC class I heavy chain. Heavy chains containing peptide associate with an invariant chain, $\beta_{2}$-microglobulin, and are processed thru the Golgi apparatus for stable expression at the host cell surface. Here, MHC class I molecules interact with T cell receptors (TCRs) on CD8+ T cells or with immunoglobulin-like killer inhibitory receptors (antigen independent) on natural killer (NK) cells (antigen dependent). The MHC class I-related protein A (MICA) is also processed through the secretory pathway for type-2 proteins, but is expressed at the cell surface in the absence of $\beta_{2}$-microglobulin or antigenic peptide. Here MICA can bind to activating receptors on the NK cell (antigen independent). Lipid-derived antigens are presented on the cell surface by the MHC-like molecule, CD1d which is also stably expressed as a trimer of heavy chain, $\beta_{2}$-microglobulin and antigen. CD1d presents antigen to natural killer T (NKT) cells bearing an invariant V $\alpha 24-\mathrm{J} \alpha \mathrm{Q} / \mathrm{V} \beta 11 \mathrm{TCR}$. Extracellular antigens bind to MHC class II molecules for presentation at the cell surface. The MHC class II molecule is processed thru the secretory pathway for direct expression at the cells surface or for transfer into the endocytic pathway. Extracellular peptides can enter the MHC class II antigen-binding groove on cellsurface-expressed MHC class II directly or after displacement from other cell surface antigenpresenting molecules. More commonly, antigen loading of MHC class II occurs within the endocytic pathway. Although chlamydiae actively prevent fusion of their intracellular inclusions with the endocytic pathway, CD4+ T cells do respond to chlamydial antigens. 
expected that much more will be learned about CPAF and about chlamydial pathogenesis and prevention in the coming years.

\section{Production of CPAF and effects on CD1d}

CPAF also interacts with the antigen presenting molecule, CD1d (Skold and Behar 2003). CD1d is similar in structure to MHC class I molecules. Like MHC class I and class II molecules, CD1 can present peptide antigens, although these peptides are typically quite hydrophobic (Boes, Stoppelenburg et al. 2009). Unlike MHC products, CD1d is monogenic and has fairly limited polymorphism. CD1d most commonly presents lipid-derived antigens from self- and pathogen-derived sources to natural killer T (NKT) cells (Porcelli 1995). CD1d molecules recognize an invariant $\mathrm{Va} 24-\mathrm{J} \alpha \mathrm{Q} / \mathrm{V} \beta 11 \mathrm{~T}$ cell receptor expressed by human NKT cells (Porcelli, Gerdes et al. 1996; Zhou 2007). CD1d recognition by invariant NKT cells results in the production of large amounts of both IL-4 and IFNY by the NKT cell that is suggested to play a role in TH1/TH2 differentiation of CD4+ T helper cells. (Taniguchi and Nakayama 2000). Using an immortalized penile urethra-derived epithelial cell line developed in our laboratory, we have demonstrated that C. trachomatis infection decreases cell surface expression of CD1d (Figure 2) (Kawana, Quayle et al. 2007). This effect was

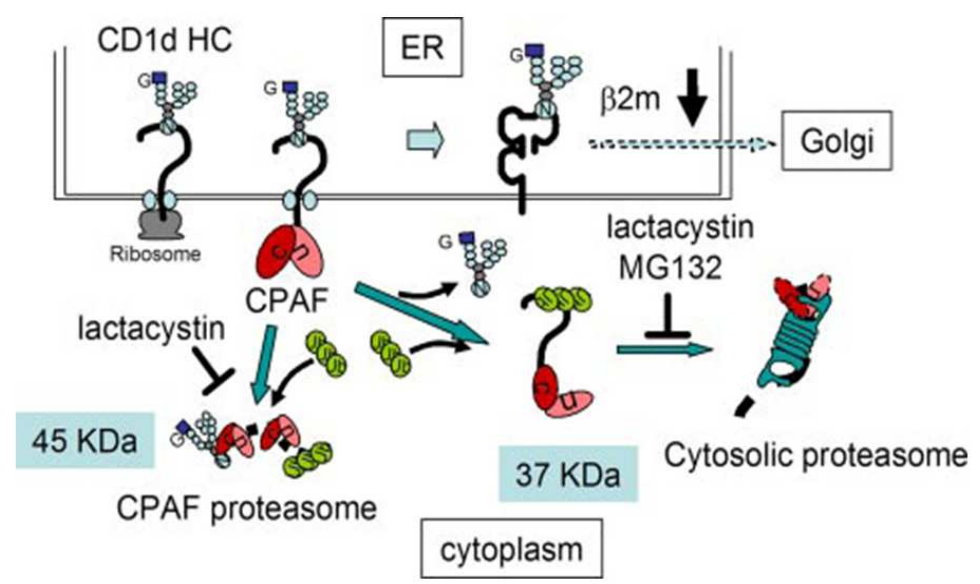

Fig. 2. Putative proteolytic degradation pathways for CD1d HCs upon C. trachomatis infection. In $C$. trachomatis-infected cells, $\beta 2 \mathrm{~m}$-unassembled CD1d HC forms accumulate in the ER due to degradation of RFX5 by CPAF. CPAF secreted from the chlamydial inclusion into the cytosol interacts with the CD1d HC via the cytoplasmic tail of CD1d and CPAF is ubiquitinated. The binding of CPAF triggers dislocation of the 45-kDa immature glycosylated form of CD1d into the cytosol. One proteolytic pathway involves the conventional cellular proteasome. Glycosylated CD1d HC is ubiquitinated in the cytosol (ubiquitin ligase), and deglycosylated (peptide N-glycosidase) to create the 37-kDa , nonglycosylated CD1d molecule. CPAF and the ubiquitinated, deglycosylated CD1d HC are degraded by the cytosolic proteasome. The alternative proteolytic pathway involves CPAFmediated degradation. The 45-kDa immature glycosylated CD1d HC interacts with CPAF. $\mathrm{CPAF}$ targets the CD1d HC for degradation by a proteolytic activity distinct from that of the cytosolic proteasome. Green symbols indicate multiubiquitins. Kawana, et. al., J Biol Chem 2001; 282(10): 7368-7375. Reproduced with permission. 
again linked to the proteasomal activity of CPAF. CPAF binds to the cytoplasmic tail of the nascent CD1d heavy chain and targets it for degradation by a CPAF-mediated pathway and via a pathway that includes the ubiquitination and deglycosylation steps integral to the conventional unfolded protein response (Kawana, Quayle et al. 2007). The immunoevasive targeting of CD1d is not unique to $C$. trachomatis. We have also shown that cell surface expression of CD1d is reduced in vitro and in vivo in human papillomavirus (HPV)-positive cells (Miura, Kawana et al. 2010). This effect can be isolated to the presence of the E5 proteins of HPV subtype 6 and HPV subtype 16, it occurs at a post-transcriptional level and it is mediated by proteasomal degradation.

In addition to known expression on standard antigen-presenting cells, CD1d is found on alternative APCs, including intestinal epithelial cells (Blumberg, Terhorst et al. 1991), epidermal keratinocytes (Bonish, Jullien et al. 2000) and basal and suprabasal cells of the vaginal, ectocervical, and penile urethral epithelia (Kawana, Matsumoto et al. 2008). In contrast, limited expression of CD1d was seen in human endocervical and endometrial tissues, the former representing the major cellular target for C. trachomatis in the female genital tract. In vitro exposure of genital tract cells to IFN $\gamma$ increased cell surface expression of CD1d in all cells studied, although the strongest induction was seen in those cells that expressed CD1d at the highest levels in vivo. Through these studies, Kawana, et. al. (Kawana, Matsumoto et al. 2008) were the first to place a functional significance on C. trachomatis-mediated reductions in cell surface expression of CD1d. Antibody-induced cross-linking of CD1d on penile urethral epithelial cells induces the secretion of IL-12 and IL-15. Cross-linking induced Th1 cytokine production was abrogated in penile urethral cells infected with C. trachomatis (Kawana, Matsumoto et al. 2008). A relative deficiency in CD1d baseline expression in the human endocervix and poor IFN $\gamma$-induced CD1d expression in penile urethral cells may make these sites particularly susceptible to pathogen transmission.

\section{Effects of C. trachomatis on surface ligand expression in directly-infected and bystander cells}

Although we and others had previously reported on C. trachomatis-mediated inhibition of IFN $\gamma$-inducible MHC class I and II expression and Cd1d expression (Zhong, Fan et al. 1999; Zhong, Liu et al. 2000; Zhong, Fan et al. 2001; Kawana, Quayle et al. 2007; Kawana, Matsumoto et al. 2008), all published experiments had been conducted via bulk analysis of mixed populations of infected cells and non-infected bystander cells. Transmission of $C$. trachomatis to the epithelial cells in the genital tract after in vivo exposure likely results in only a small population of infected cells. Some in vitro protocols exist that can result in infection of a very high proportion of $C$. trachomatis-infected epithelial cells, but this does not reflect in vivo infection characteristics. Other infection protocols used for in vitro study of host immune response to $C$. trachomatis infection result in a mixed population of $C$. trachomatis-exposed cells and uninfected, bystander cells. Bulk analysis of these mixed populations, however, dilutes changes that may occur in only one of these subpopulations. We hypothesized that separation of these cellular subpopulations, when combined with side-by-side analyses, would allow a more inclusive and accurate assessment of the overall impact of $C$. trachomatis on host epithelial cell immune response. 
We have recently completed and published our first investigation on C. trachomatis immune evasion strategies that stratified cells by infection status to allow independent assessment of immune cell ligands on infected and uninfected host epithelial cells in a single culture (Ibana, Schust et al. 2011). Using flow cytometry to separate C. trachomatis-infected cells from those non-infected bystander cells, we were able to investigate the possible indirect effects of soluble factors released during C. trachomatis infection on uninfected cells. We hypothesized that investigating the effects of $C$. trachomatis in both infected and uninfected bystander cells would promote a better understanding of the immunological milieu induced by $C$. trachomatis at the local site of infection and concentrated our initial efforts on the MHC class I molecule.

Natural killer (NK) cells and CD8+ T cells are important components of the host cellular immune defense against intracellular microorganisms (Figure 1). Each of these immune cell subpopulations can mediate their protective immune activities via two mechanisms: (1) direct cytolysis and (2) secretion of IFN $\gamma$ and other cytokines [reviewed in (Trinchieri 1989). Direct cytolytic activities are induced by the interaction of cell surface receptors on NK cells and CD8+ T cells with the ligands expressed on the surface of target cells. CD8+ T cells can lyse target cells that express cognate antigens presented by the target cell MHC class I molecule. The immunologic activity of NK cells results from a summation of signals mediated through NK cell-expressed activating and inhibitory receptors (Moretta et al. 2001). Unlike those of CD8+ T cells, NK cell ligand-mediated interactions are typically antigen-independent. While MHC class I products bind to an inhibitory class of NK cell killer immunoglobulin-like receptors (KIRs) to aid in self/non-self recognition, other ligands on host cells can bind to activating NK cell receptors. One such molecule, the target cellexpressed MHC class I-related protein A (MICA), primarily functions as a ligand for the NK cell activating receptor, NKG2D (Bauer, Groh et al. 1999). It is well-documented that modulation of the expression of these ligands on host cells is one of the primary strategies that intracellular microorganisms use to evade immune cell recognition. Intracellular microorganisms that can diminish surface expression of MHC class I by their host cells are more impervious to CD8+ T cell activity. However, the loss of MHC class I at the cell surface may make the infected host cells more susceptible to cytolytic NK cell activity when the interacting NK cell expresses a predominance of activating NK cell receptors (Ljunggren and Karre 1990) In short, co-evolution alongside human pathogens may have driven the development of host NK cells to counter the ability of some intracellular pathogens to evade immune detection via downregulation of host MHC class I expression.

By examining directly-infected and uninfected bystander cells separately, we have shown that MHC class I downregulation in the presence of $C$. trachomatis is mediated by direct and indirect (soluble) factors (Ibana, Schust et al. 2011) In contrast, we now have preliminary data suggesting that MICA expression is altered in C. trachomatis-infected cells but not in bystander, uninfected cells (Ibana, Aiyar et al. 2012). C. trachomatis infection of epithelial cells alters two well-documented characteristics of infected cultures: (a) their immune cells ligand expression (Soderlund and Kihlstrom 1982; Zhong, Fan et al. 1999; Zhong, Liu et al. 2000; Kawana, Quayle et al. 2007; Ibana, Nagamatsu et al. 2011) and (b) the extent and nature of epithelial cell chemokine and cytokine secretion (Rasmussen, Eckmann et al. 1997). Changes in the cell surface expression of immune cell ligands on epithelial cells at the local site of $C$. trachomatis infection may reflect the susceptibility of these cells to host immune cell 
mediated activities, while the secretion of soluble factors can facilitate the migration of host immune cells to the infected site. We hypothesize that these soluble factors may play an important role in the cross-talk between C. trachomatis-infected cells and neighboring uninfected cells. We are presently in the process of further defining the host soluble factor or factors that may be responsible for the decrease in MHC class I surface expression on uninfected-bystander cells in C. trachomatis serovar D-infected endocervical epithelial cell (A2EN) cultures, and suspect there may be several factors involved.

\section{MHC class I expression after infection with genital and disseminating C. trachomatis serovars}

As a corollary to these observations, we find it intriguing to comment on reports showing that a lymphogranuloma venereum (LGV) serovar of $C$. trachomatis, which causes a disseminated form of infection, utilizes CPAF to downregulate both constitutive and IFN $\gamma$ induced MHC class I expression in cervical epithelial (HeLa) cells (Zhong, Liu et al. 2000; Zhong, Fan et al. 2001). This finding was interpreted by the investigators to represent an important mechanism for immune evasion of $\mathrm{CD} 8+\mathrm{T}$ cell recognition by $\mathrm{C}$. trachomatis. We have confirmed the LGV modulation of MHC class I in our own experiments (Figure 3) However, using C. trachomatis serovar D, which causes local infection within the female genital tract, we have seen that the level of MHC class I down regulation is less than after serovar LGV infection and that IFN $\gamma$ attenuates the down-modulation of MHC class I expression in C. trachomatis-infected cells and in bystander, uninfected cells (Ibana, Schust et al. 2011). Rather, MHC class I expression in IFN $\gamma$-exposed cells remains similar to that in mock-infected controls (Figure 3).
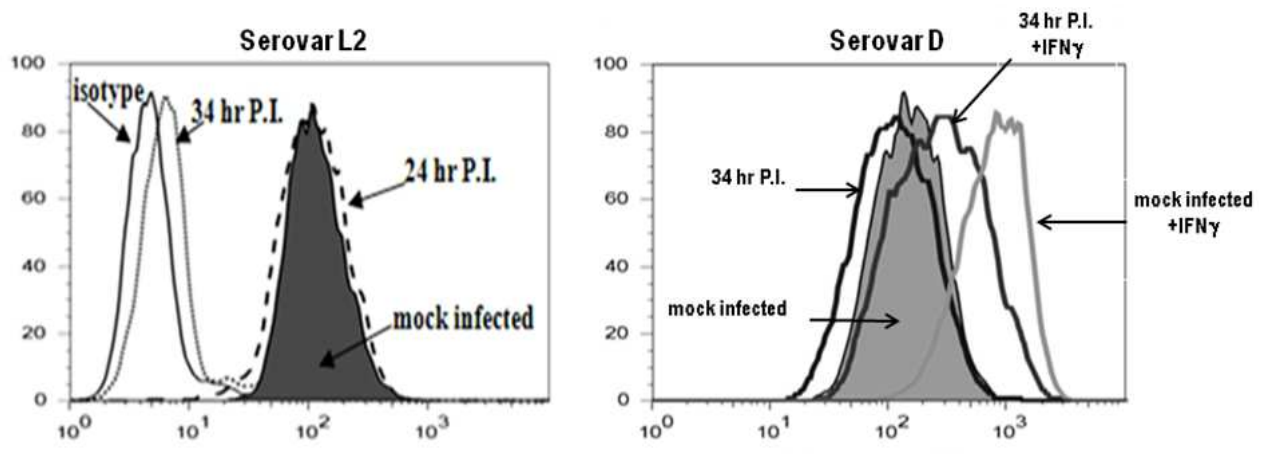

MHC class I surface expression

Fig. 3. MHC class I modulation after exposure to non-disseminating (serovar D) and disseminating (serovar L2) genital C. trachomatis. Primary-like endocervical epithelial cells (A2EN) were infected with C. trachomatis serovar L2 or serovar D. Surface MHC class I expression was quantitated in chlamydial-LPS-positive cells gated by flow cytometry. A dramatic decrease in the surface expression of MHC class I was observed in A2EN cells infected with serovar L2 at 34 hours post infection (hpi); those infected with serovar D exhibited much smaller decreases in MHC class I expression. Although the IFN $\gamma$-induced increase in MHC class I was noted in both infected and uninfected cells, it was attenuated with C. trachomatis serovar D infection. 
These results may suggest that genital C. trachomatis serovars do not utilize evasion of CD8+ $\mathrm{T}$ cell recognition via MHC class I modulation to the extent that disseminating serovars do. Supporting our observations are reports that chlamydia-specific CD8 $+\mathrm{T}$ cells are fully capable of lysing epithelial cells infected with genital serovars of $C$. trachomatis (Roan and Starnbach 2006; Grotenbreg, Roan et al. 2008). Others have noted differences in vitro in the innate immune responses to genital $C$. trachomatis serovar $E$ and disseminating $C$. trachomatis serovar L2 infection of HeLa cells (Dessus-Babus, Knight et al. 2000). In vivo, the former results in local or ascending infection with canalicular spread along genital mucosal surfaces. In contrast, disseminating chlamydial disease is a sub-mucosal infection with rapid spread to regional lymph nodes (Schachter and Osoba 1983). In vitro, the release of the antiinflammatory cytokine IL-11 was increased in HeLa cells infected with C. trachomatis serovar L2 when compared to cells infected with the non-disseminating genital serovar E (DessusBabus, Knight et al. 2000). Although the mechanism for differences in MHC class I modulation between the Serovar D- and LGV-infected cells remains unknown, this observation may also help to explain the localization of infection with genital C. trachomatis serovars but disseminated disease after infection by LGV serovars and certainly warrants further investigations. Since MHC class I down-regulation is linked to CPAF activity (Zhong, Liu et al. 2000; Zhong, Fan et al. 2001), this could be a protein of interest, as would other secreted chlamydial proteins.

\section{Conclusions}

Host-pathogen co-evolution drives adaptations in each partner that ensure survival of the host and propagation of the pathogen. This often involves sophisticated methods of injury evasion but neither the host nor the pathogen typically acquires complete protection. Rather, compromises are met that partially benefit both partners. For C. trachomatis and its human host, this balance could be typified by the concept of chlamydial persistence. Persistent growth in vitro is promoted by exogenous growth conditions that are stressful to the pathogen, but re-initiation of the productive growth cycle occurs when these stressors are removed. Although there is currently no direct human in vivo evidence for chlamydial persistence due to the very challenging nature of these types of investigations, we have postulated that this phenomenon may protect the host from relatively prolonged and/or intense immune-induced pathologies. On the other hand, chlamydial persistence may also provide a mechanism that enables the pathogen to establish prolonged infection and reinfection even though this may be disadvantageous to some hosts over time. From this perspective, persistence may be perceived as an adaptation that may facilitate long-term association of pathogen and host.

While a precarious balance must be struck between $C$. trachomatis and its host, we have here concentrated on several ways in which $C$. trachomatis evades host immune detection through modulation of surface ligands involved in antigen presentation. Since host response to chlamydial infections involves innate and adaptive immune cells, we have addressed mechanisms by which chlamydia can evade destruction by CD4+ and CD8+ T cells, as well as NK and NKT cells. We have reviewed data generated by ourselves and others on modulation of surface expression of MHC class I, MHC class II, CD1d and MICA. While the majority of these modulations appear to be advantageous only for the infecting pathogen, we have recently begun to look at direct and soluble mediators of these effects and their temporal initiation post-infection in an effort to better understand the host response to 
immune evasion. Finally, we have begun to dissect serovar-specific differences in host cell surface ligand modulation as a means of gaining a more complete understanding of the pathogenesis of localized, ascending and disseminating infections with genital $C$. trachomatis. Continued study of host-pathogen interactions should help us to better address the epidemiology of $C$. trachomatis infection and to develop more effective disease treatment and prevention paradigms.

\section{References}

Abromaitis, S. and R. S. Stephens (2009). "Attachment and entry of Chlamydia have distinct requirements for host protein disulfide isomerase." PLoS Pathog 5(4): e1000357.

AbdelRahman, Y. M. and R. J. Belland (2005). "The chlamydial developmental cycle". FEMS Microbiol Rev 29:949-959.

Agrawal, T., A. R. Bhengraj, et al. (2011). "Expression of TLR 2, TLR 4 and iNOS in Cervical Monocytes of Chlamydia trachomatis-infected Women and Their Role in Host Immune Response." Am J Reprod Immunol. 66(6):534-543.

Bauer, S., V. Groh, et al. (1999). "Activation of NK cells and T cells by NKG2D, a receptor for stress-inducible MICA." Science 285(5428): 727-729.

Beatty, W. L., T. A. Belanger, et al. (1994). "Role of tryptophan in gamma interferonmediated chlamydial persistence." Ann N Y Acad Sci 730: 304-306.

Beatty, W. L., G. I. Byrne, et al. (1993). "Morphologic and antigenic characterization of interferon gamma-mediated persistent Chlamydia trachomatis infection in vitro." Proc Natl Acad Sci U S A 90(9): 3998-4002.

Beatty, W. L., G. I. Byrne, et al. (1994). "Repeated and persistent infection with Chlamydia and the development of chronic inflammation and disease." Trends Microbiol 2(3): 94-98.

Beatty, W. L., R. P. Morrison, et al. (1994). "Persistent chlamydiae: from cell culture to a paradigm for chlamydial pathogenesis." Microbiol Rev 58(4): 686-699.

Beatty, W. L., R. P. Morrison, et al. (1995). "Reactivation of persistent Chlamydia trachomatis infection in cell culture." Infect Immun 63(1): 199-205.

Bednar, M. M., I. Jorgensen, et al. (2011). "Chlamydia Protease-like Activity Factor (CPAF): Characterization of Proteolysis Activity in vitro and Development of a Nanomolar Affinity CPAF Zymogen-Derived Inhibitor." Biochemistry. 50(35):7441-7443.

Belland, R. J., D. E. Nelson, et al. (2003). "Transcriptome analysis of chlamydial growth during IFN-gamma-mediated persistence and reactivation." Proc Natl Acad Sci U S A 100(26): 15971-15976.

Belland, R.J., G. Zhong, et al. (2003). "Genomic transcriptional profiling of the developmental cycle of Chlamydia trachomatis." Proc Natl Acad Sci USA 100(14):8478-8483.

Betts, H. J., K. Wolf, et al. (2009). "Effector protein modulation of host cells: examples in the Chlamydia spp. arsenal." Curr Opin Microbiol 12(1): 81-87.

Blumberg, R. S., C. Terhorst, et al. (1991). "Expression of a nonpolymorphic MHC class I-like molecule, CD1D, by human intestinal epithelial cells." J Immunol 147(8): 2518-2524. 
Boes, M., A. J. Stoppelenburg, et al. (2009). "Endosomal processing for antigen presentation mediated by CD1 and Class I major histocompatibility complex: roads to display or destruction." Immunology 127(2): 163-170.

Bonish, B., D. Jullien, et al. (2000). "Overexpression of CD1d by keratinocytes in psoriasis and CD1d-dependent IFN-gamma production by NK-T cells." J Immunol 165(7): 4076-4085.

Bragina, E. Y., M. A. Gomberg, et al. (2001). "Electron microscopic evidence of persistent chlamydial infection following treatment." J Eur Acad Dermatol Venereol 15(5): 405-409.

Brunham, R. C. and J. Rey-Ladino (2005). "Immunology of Chlamydia infection: implications for a Chlamydia trachomatis vaccine." Nat Rev Immunol 5(2): 149-161.

Byrne, G. I. and D. A. Krueger (1983). "Lymphokine-mediated inhibition of Chlamydia replication in mouse fibroblasts is neutralized by anti-gamma interferon immunoglobulin." Infect Immun 42(3): 1152-1158.

Campbell, S., J. Larsen, et al. (1998). "Chlamydial elementary bodies are translocated on the surface of epithelial cells." Am J Pathol 152(5): 1167-1170.

Carabeo, R. A., D. J. Mead, et al. (2003). "Golgi-dependent transport of cholesterol to the Chlamydia trachomatis inclusion." Proc Natl Acad Sci U S A 100(11): 6771-6776.

CDC. (2010). "2009 Sexually transmitted disease surveillance." from http://www.cdc.gov/std/stats09/chlamydia.htm.

Chang, C. H., J. D. Fontes, et al. (1994). "Class II transactivator (CIITA) is sufficient for the inducible expression of major histocompatibility complex class II genes." J Exp Med 180(4): 1367-1374.

Chen, D., L. Lei, et al. (2010). "Characterization of Pgp3, a Chlamydia trachomatis plasmidencoded immunodominant antigen." J Bacteriol 192(22): 6017-6024.

Clark, R. B., P. F. Schatzki, et al. (1982). "Ultrastructural effect of penicillin and cycloheximide on Chlamydia trachomatis strain HAR-13." Med Microbiol Immunol 171(3): 151-159.

Clifton, D. R., K. A. Fields, et al. (2004). "A chlamydial type III translocated protein is tyrosine-phosphorylated at the site of entry and associated with recruitment of actin." Proc Natl Acad Sci U S A 101(27): 10166-10171.

Cocchiaro, J. L. and R. H. Valdivia (2009). "New insights into Chlamydia intracellular survival mechanisms." Cell Microbiol 11(11): 1571-1578.

Conant, C. G. and R. S. Stephens (2007). "Chlamydia attachment to mammalian cells requires protein disulfide isomerase." Cell Microbiol 9(1): 222-232.

Davis, C. H., J. E. Raulston, et al. (2002). "Protein disulfide isomerase, a component of the estrogen receptor complex, is associated with Chlamydia trachomatis serovar E attached to human endometrial epithelial cells." Infect Immun 70(7): 3413-3418.

Dean, D., R. J. Suchland, et al. (2000). "Evidence for long-term cervical persistence of Chlamydia trachomatis by omp1 genotyping." J Infect Dis 182(3): 909-916.

Dessus-Babus, S., S. T. Knight, et al. (2000). "Chlamydial infection of polarized HeLa cells induces PMN chemotaxis but the cytokine profile varies between disseminating and non-disseminating strains." Cell Microbiol 2(4): 317-327. 
Everett, K. D., R. M. Bush, et al. (1999). "Emended description of the order Chlamydiales, proposal of Parachlamydiaceae fam. nov. and Simkaniaceae fam. nov., each containing one monotypic genus, revised taxonomy of the family Chlamydiaceae, including a new genus and five new species, and standards for the identification of organisms." Int J Syst Bacteriol 49 Pt 2: 415-440.

Feng, G. S. and M. W. Taylor (1989). "Interferon gamma-resistant mutants are defective in the induction of indoleamine 2,3-dioxygenase." Proc Natl Acad Sci U S A 86(18): 7144-7148.

Fields, K. A., E. Fischer, et al. (2002). "Inhibition of fusion of Chlamydia trachomatis inclusions at 32 degrees $\mathrm{C}$ correlates with restricted export of IncA." Infect Immun 70(7): 3816-3823.

Finco, O., E. Frigimelica, et al. (2011). "Approach to discover T- and B-cell antigens of intracellular pathogens applied to the design of Chlamydia trachomatis vaccines." Proc Natl Acad Sci U S A 108(24): 9969-9974.

Fischer, W., S. Prassl, et al. (2009). "Virulence mechanisms and persistence strategies of the human gastric pathogen Helicobacter pylori." Curr Top Microbiol Immunol 337: 129-171.

Fruh, K., K. Ahn, et al. (1997). "Inhibition of MHC class I antigen presentation by viral proteins." J Mol Med (Berl) 75(1): 18-27.

Gerbase, A. C., J. T. Rowley, et al. (1998). "Global epidemiology of sexually transmitted diseases." Lancet 351 Suppl 3: 2-4.

Germain, R. N. (1986). "Immunology. The ins and outs of antigen processing and presentation." Nature 322(6081): 687-689.

Giles, D. K., J. D. Whittimore, et al. (2006). "Ultrastructural analysis of chlamydial antigencontaining vesicles everting from the Chlamydia trachomatis inclusion." Microbes Infect 8(6): 1579-1591.

Giles, D. K. and P. B. Wyrick (2008). "Trafficking of chlamydial antigens to the endoplasmic reticulum of infected epithelial cells." Microbes Infect 10(14-15): 1494-1503.

Gobin, S. J., A. Peijnenburg, et al. (1998). "The RFX complex is crucial for the constitutive and CIITA-mediated transactivation of MHC class I and beta2-microglobulin genes." Immunity 9(4): 531-541.

Grotenbreg, G. M., N. R. Roan, et al. (2008). "Discovery of CD8+ T cell epitopes in Chlamydia trachomatis infection through use of caged class I MHC tetramers." Proc Natl Acad Sci U S A 105(10): 3831-3836.

Hellstrom, W. J., J. Schachter, et al. (1987). "Is there a role for Chlamydia trachomatis and genital mycoplasma in male infertility?" Fertil Steril 48(2): 337-339.

Holland, S. M., A. P. Hudson, et al. (1992). "Demonstration of chlamydial RNA and DNA during a culture-negative state." Infect Immun 60(5): 2040-2047.

Horst, D., M. E. Ressing, et al. (2011). "Exploiting human herpesvirus immune evasion for therapeutic gain: potential and pitfalls." Immunol Cell Biol 89(3): 359-366.

Hower, S., K. Wolf, et al. (2009). "Evidence that CT694 is a novel Chlamydia trachomatis T3S substrate capable of functioning during invasion or early cycle development." Mol Microbiol 72(6): 1423-1437.

Hybiske, K. and R. S. Stephens (2007a). "Mechanisms of Chlamydia trachomatis entry into nonphagocytic cells." Infect Immun 75(8): 3925-3934. 
Hybiske, K. and R. S. Stephens (2007b). "Mechanisms of host cell exit by the intracellular bacterium Chlamydia." Proc Natl Acad Sci U S A 104(27): 11430-11435.

Ibana J. A., A. Aiyar, et al. (2012). "Modulation of MICA on the surface of Chlamydia trachomatis-infected endocervical epithelial cells promotes NK cell-mediated killing." FEMS Immunol Med Microbiol (in press).

Ibana, J. A., T. Nagamatsu, et al. (2011). "Attenuation of IDO1 activity by 1-methyl tryptophan blocks IFN $\gamma$-induced Chlamydia trachomatis persistence in human epithelial cells." Infect Immun 79(11):4425-4437.

Ibana, J. A., D. J. Schust, et al. (2011). "Chlamydia trachomatis immune evasion via downregulation of MHC class I surface expression involves direct and indirect mechanisms." Infect Dis Obstet Gynecol 2011: 420905.

Idahl, A., L. Abramsson, et al. (2007). "Male serum Chlamydia trachomatis IgA and IgG, but not heat shock protein 60 IgG, correlates with negatively affected semen characteristics and lower pregnancy rates in the infertile couple." Int J Androl 30(2): 99-107.

Joki-Korpela, P., N. Sahrakorpi, et al. (2009). "The role of Chlamydia trachomatis infection in male infertility." Fertil Steril 91(4 Suppl): 1448-1450.

Kawana, K., J. Matsumoto, et al. (2008). "Expression of CD1d and ligand-induced cytokine production are tissue specific in mucosal epithelia of the human lower reproductive tract." Infect Immun 76(7): 3011-3018.

Kawana, K., A. J. Quayle, et al. (2007). "CD1d degradation in Chlamydia trachomatisinfected epithelial cells is the result of both cellular and chlamydial proteasomal activity." J Biol Chem 282(10): 7368-7375.

Kelly, K. A., J. C. Walker, et al. (2000). "Differential regulation of CD4 lymphocyte recruitment between the upper and lower regions of the genital tract during Chlamydia trachomatis infection." Infect Immun 68(3): 1519-1528.

Linhares, I. M. and S. S. Witkin (2010). "Immunopathogenic consequences of Chlamydia trachomatis $60 \mathrm{kDa}$ heat shock protein expression in the female reproductive tract." Cell Stress Chaperones 15(5): 467-473.

Ljunggren, H. G. and K. Karre (1990). "In search of the 'missing self': MHC molecules and NK cell recognition." Immunol Today 11(7): 237-244.

Marks, E., M. A. Tam, et al. (2010). "The female lower genital tract is a privileged compartment with IL-10 producing dendritic cells and poor Th1 immunity following Chlamydia trachomatis infection." PLoS Pathog 6(11): e1001179.

Matthews, K., K. A. Wilkinson, et al. (2011). "Predominance of interleukin-22 over interleukin-17 at the site of disease in human tuberculosis." Tuberculosis (Edinb).

Maudsley, D. J. and A. G. Morris (1989). "Regulation of IFN-gamma-induced host cell MHC antigen expression by Kirsten MSV and MLV. I. Effects on class I antigen expression." Immunology 67(1): 21-25.

Miura, S., K. Kawana, et al. (2010). "CD1d, a sentinel molecule bridging innate and adaptive immunity, is downregulated by the human papillomavirus (HPV) E5 protein: a possible mechanism for immune evasion by HPV." J Virol 84(22): 11614-11623. 
Nelson, D. E., D. P. Virok, et al. (2005). "Chlamydial IFN-gamma immune evasion is linked to host infection tropism." Proc Natl Acad Sci U S A 102(30): 10658-10663.

Nicholson, T. L., L. Olinger, et al. (2003). "Global stage-specific gene regulation during the developmental cycle of Chlamydia trachomatis." J Bacteriol 185(10):3179-3189.

Ohman, H., A. Tiitinen, et al. (2011). "Cytokine gene polymorphism and Chlamydia trachomatis-specific immune responses." Hum Immunol 72(3): 278-282.

Paavonen, J. and M. Lehtinen (1996). "Chlamydial pelvic inflammatory disease." Hum Reprod Update 2(6): 519-529.

Patel, M., M. Stefanidou, et al. (2011). "Dynamics of cell-mediated immune responses to cytomegalovirus in pediatric transplantation recipients." Pediatr Transplant (epub July 18). 10(1):18-28.

Patton, D. L., M. Askienazy-Elbhar, et al. (1994). "Detection of Chlamydia trachomatis in fallopian tube tissue in women with postinfectious tubal infertility." Am J Obstet Gynecol 171(1): 95-101.

Peipert, J. F. (2003). "Clinical practice. Genital chlamydial infections." N Engl J Med 349(25): 2424-2430.

Ploegh, H. L. (1998). "Viral strategies of immune evasion." Science 280(5361): 248-253.

Porcelli, S., D. Gerdes, et al. (1996). "Human T cells expressing an invariant V alpha 24-J alpha Q TCR alpha are CD4- and heterogeneous with respect to TCR beta expression." Hum Immunol 48(1-2): 63-67.

Porcelli, S. A. (1995). "The CD1 family: a third lineage of antigen-presenting molecules." Adv Immunol 59: 1-98.

Qi, M., S. Gong, et al. (2011). "A Chlamydia trachomatis OmcB C-terminal fragment is released into the host cell cytoplasm and is immunogenic in humans." Infect Immun 79(6): 2193-2203.

Rank, R. G., A. K. Bowlin, et al. (2000). "Characterization of lymphocyte response in the female genital tract during ascending Chlamydial genital infection in the guinea pig model." Infect Immun 68(9): 5293-5298.

Rasmussen, S. J., L. Eckmann, et al. (1997). "Secretion of proinflammatory cytokines by epithelial cells in response to Chlamydia infection suggests a central role for epithelial cells in chlamydial pathogenesis." J Clin Invest 99(1): 77-87.

Reveneau, N., D. D. Crane, et al. (2005). "Bactericidal activity of first-choice antibiotics against gamma interferon-induced persistent infection of human epithelial cells by Chlamydia trachomatis." Antimicrob Agents Chemother 49(5): 1787-1793.

Roan, N. R. and M. N. Starnbach (2006). "Antigen-specific CD8+ T cells respond to Chlamydia trachomatis in the genital mucosa." J Immunol 177(11): 7974-7979.

Roan, N. R. and M. N. Starnbach (2008). "Immune-mediated control of Chlamydia infection." Cell Microbiol 10(1): 9-19.

Rours, G. I., L. Duijts, et al. (2011). "Chlamydia trachomatis infection during pregnancy associated with preterm delivery: a population-based prospective cohort study." Eur J Epidemiol 26(6): 493-502.

Schachter, J. and A. O. Osoba (1983). "Lymphogranuloma venereum." Br Med Bull 39(2): 151154. 
Sharma, J., A. M. Bosnic, et al. (2004). "Human antibody responses to a Chlamydia-secreted protease factor." Infect Immun 72(12): 7164-7171.

Skold, M. and S. M. Behar (2003). "Role of CD1d-restricted NKT cells in microbial immunity." Infect Immun 71(10): 5447-5455.

Soderlund, G. and E. Kihlstrom (1982). "Physicochemical surface properties of elementary bodies from different serotypes of chlamydia trachomatis and their interaction with mouse fibroblasts." Infect Immun 36(3): 893-899.

Stephens, A.J., M. Aubuchon, et al. (2011) "Antichlamydial antibodies, human fertility and pregnancy wastage." Inf Dis Obstet Gynecol (e-pub ahead of print).

Sziller, I., P. Fedorcsak, et al. (2008). "Circulating antibodies to a conserved epitope of the Chlamydia trachomatis $60-\mathrm{kDa}$ heat shock protein is associated with decreased spontaneous fertility rate in ectopic pregnant women treated by salpingectomy." Am J Reprod Immunol 59:99-104.

Taniguchi, M. and T. Nakayama (2000). "Recognition and function of Valpha14 NKT cells." Semin Immunol 12(6): 543-550.

Todd, W. J. and H. D. Caldwell (1985). "The interaction of Chlamydia trachomatis with host cells: ultrastructural studies of the mechanism of release of a biovar II strain from HeLa 229 cells." J Infect Dis 151(6): 1037-1044.

Tortorella, D., B. E. Gewurz, et al. (2000). "Viral subversion of the immune system." Annu Rev Immunol 18: 861-926.

Trinchieri, G. (1989). "Biology of natural killer cells." Adv Immunol 47: 187-376.

van den Elsen, P. J. and S. J. Gobin (1999). "The common regulatory pathway of MHC class I and class II transactivation." Microbes Infect 1(11): 887-892.

Van Voorhis, W. C., L. K. Barrett, et al. (1996). "Analysis of lymphocyte phenotype and cytokine activity in the inflammatory infiltrates of the upper genital tract of female macaques infected with Chlamydia trachomatis." J Infect Dis 174(3): 647-650.

Wang, J., K. J. Frohlich, et al. (2011). "Altered protein secretion of Chlamydia trachomatis in persistently infected human endocervical epithelial cells." Microbiology. 157(Pt 10):2759-2771.

Witkin, S. S. (1999). "Immunity to heat shock proteins and pregnancy outcome." Infect Dis Obstet Gynecol 7(1-2): 35-38.

Wyrick, P. B. (2010). "Chlamydia trachomatis persistence in vitro: an overview." J Infect Dis 201 Suppl 2: S88-95.

Xiao, T. S. (2010). "Subversion of innate immune signaling through molecular mimicry." J Clin Immunol 30(5): 638-642.

Zhong, G., P. Fan, et al. (2001). "Identification of a chlamydial protease-like activity factor responsible for the degradation of host transcription factors." J Exp Med 193(8): 935-942.

Zhong, G., T. Fan, et al. (1999). "Chlamydia inhibits interferon gamma-inducible major histocompatibility complex class II expression by degradation of upstream stimulatory factor 1." J Exp Med 189(12): 1931-1938.

Zhong, G., L. Liu, et al. (2000). "Degradation of transcription factor RFX5 during the inhibition of both constitutive and interferon gamma-inducible major histocompatibility complex class I expression in chlamydia-infected cells." J Exp Med 191(9): 1525-1534. 
Zhou, D. (2007). "OX40 signaling directly triggers the antitumor effects of NKT cells." J Clin Invest 117(11): 3169-3172. 


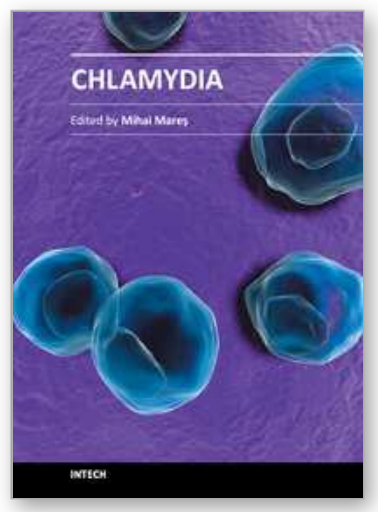

\author{
Chlamydia \\ Edited by Prof. Mihai Mares
}

ISBN 978-953-51-0470-4

Hard cover, 358 pages

Publisher Intech

Published online 30, March, 2012

Published in print edition March, 2012

Nowadays, Chlamydia still represents a redoubtable pathogen. Among its consequences, the blindness in children and severe impairment of reproductive health in adults are the most mutilating. Worldwide, it is estimated that six million of people suffer from post-trachoma blindness and almost 90 million become sexually infected each year. Due to its silent evolution and sexually transmission, the chlamydial infection can occur in anyone. The book "Chlamydia - A Multifaceted Pathogen" contains an updated review of all-important issues concerning the chlamydial infection. It comprises 18 chapters grouped in four major parts dealing with etiology and pathogenicity, clinical aspects, diagnosis and prevention. The new molecular data about the pathogenicity and the exhaustive presentation of clinical findings bring novelty to the book and improve our knowledge about Chlamydia induced diseases.

\title{
How to reference
}

In order to correctly reference this scholarly work, feel free to copy and paste the following:

Gerialisa Caesar, Joyce A. Ibana, Alison J. Quayle and Danny J. Schust (2012). Host-Pathogen Co-Evolution: Chlamydia trachomatis Modulates Surface Ligand Expression in Genital Epithelial Cells to Evade Immune Recognition, Chlamydia, Prof. Mihai Mares (Ed.), ISBN: 978-953-51-0470-4, InTech, Available from: http://www.intechopen.com/books/chlamydia/host-pathogen-co-evolution-chlamydia-trachomatis-modulatessurface-ligand-expression-in-genital-epit

\section{INTECH}

open science | open minds

\section{InTech Europe}

University Campus STeP Ri

Slavka Krautzeka 83/A

51000 Rijeka, Croatia

Phone: +385 (51) 770447

Fax: +385 (51) 686166

www.intechopen.com

\section{InTech China}

Unit 405, Office Block, Hotel Equatorial Shanghai No.65, Yan An Road (West), Shanghai, 200040, China 中国上海市延安西路65号上海国际贵都大饭店办公楼405单元 Phone: +86-21-62489820

Fax: $+86-21-62489821$ 
(C) 2012 The Author(s). Licensee IntechOpen. This is an open access article distributed under the terms of the Creative Commons Attribution 3.0 License, which permits unrestricted use, distribution, and reproduction in any medium, provided the original work is properly cited. 